\title{
Optimum design of a CCHP system based on Economical, energy and environmental considerations using GA and PSO
}

\author{
Masoud Rabbani*, Setare Mohammadi and Mahdi Mobini
}

Department of Industrial Engineering, University of Tehran, Tehran, Iran

\begin{tabular}{l} 
C H R O N I C L E \\
\hline Article history: \\
Received January 152017 \\
Received in Revised Format \\
April 12017 \\
Accepted April 22017 \\
Available online \\
April 42017 \\
\hline Keywords: \\
Combined cooling heating power \\
generation \\
Optimised design \\
Control strategy \\
Particle Swarm Optimisation \\
Genetic algorithm
\end{tabular}

\section{Introduction}

A large portion of national energy consumption is expended for fulfilling the buildings' heating, cooling, and electricity demand. Consumed energy in the buildings sector, consisting of residential and commercial end users, accounts for $20.1 \%$ of the total delivered energy consumption worldwide (International Energy Outlook, 2016). The type and amount of energy consumed by households can vary significantly within and across regions and countries (International Energy Outlook, 2016). In the USA, residential buildings consume $22 \%$ of the total final energy use, compared with $26 \%$ in the EU. Residential buildings energy consumption is $28 \%$ of total energy consumption in the UK, well above Spain at $15 \%$, mainly due to a more severe climate and the building types. In 2030 , energy consumption attributed to residential and the non-domestic sectors is predicted to reach to $67 \%$ and $33 \%$, respectively (Pérez-Lombard et al., 2008). Lack of efficient construction regulations, in addition to the low energy

* Corresponding author

E-mail: mrabbani@ut.ac.ir (M. Rabbani)

(C) 2018 Growing Science Ltd. All rights reserved. doi: $10.5267 /$ j. ijiec.2017.4.002 
prices in the past have caused careless and inefficient consumption of energy by the Iranian residential sector compared to industrialized countries (Karbassi et al., 2007). Commercial and residential building sector consume about $40 \%$ of total energy in Iran. This consists, $11.7 \%$ of oil products, $73.13 \%$ of natural gas and $13.25 \%$ of electricity (Iran Energy Efficiency Organization (IEEO-SABA), 2016). In addition to the economic burdens, this energy consumption trend all around the world is causing severe environmental problems as well as energy security issues (Cai et al., 2009).

Using Combined Cooling, Heating and Power generation system (CCHP) is a proven method for enhancing energy efficiency. Using CCHPs leads to economic savings, while reducing the emissions (Zheng et al., 2014). Also, possible energy sources for CCHP systems include a vast range of fossil fuels, biomass, geothermal and solar power, giving the flexibility desired for installing these systems in different geographical regions. Consequently, CCHP systems are installed in a variety of buildings, such as hotels, offices, hospitals and supermarkets (Ge et al., 2009; Wang et al., 2008).

In this field the goal is to fulfil a building's energy demand while minimizing the costs and environmental consequences (Løken, 2007). In order to do so, structural design and operational planning of the system need to be optimised. Structural design of the system relates to defining the optimum number and capacity of the equipment; and operational planning of the system relates to the determination of the hourly operation of the equipment (Mago \& Chamra, 2009). One of the main challenges in energy planning field is access to reliable estimation of energy demand. Additionally, the fluctuations in the building energy demand (in terms of heating, cooling, and electricity) makes the design and operational planning of the system a complex task $(\mathrm{CaO}, 2009)$ since reaching the optimum design requires solving an optimisation model at every interval of time. The large scale of the optimisation problem makes the models computationally intractable; therefore, operating strategies are proposed to reduce the complexity of the models. These strategies determine the state of the Power Generation Unit (PGU) and the proportion of the cooling demand fulfilled by the electric chillers (so called "electric cooling to cool load ratio") in each period, which significantly reduce the complexity of the problem. A variety of methods for determining optimum design of CCHP systems are proposed. Initially linear optimisation models were developed to design energy systems. Cao (2009) analysed the influence of energy prices on the system's economic feasibility. The objective function was minimisation of the annual cost, and maximization of the exegetic efficiency. Piacentino and Cardona (2008) presented a Mixed Integer Linear Programing (MILP) model to optimize the economic and environmental performance of a tri-generation system (heating, cooling and electricity production). Nonlinear Programming (NLP) and Mixed Integer Programming (MIP) models were used to find the optimum design of the system in research by Gamou and Yokoyama (1998) and Arcuri et al. (2007), respectively. Reduced gradient method was used by Chen and Hong (1996) to solve the presented mathematical model. In a similar study a matrix approach was employed to model the problem by Geidl and Andresson (2007). They presented the mathematical model of the problem in the matrix form and used Sequential Quadratic Programming to optimize an hourly linear objective function.

Due to their capability in tackling large-scale optimisation problems, artificial intelligence, in the form of heuristic and metaheuristic algorithms are commonly employed to optimize the design and operation of CCHP systems. Metaheuristic algorithms' ability of exploration and exploitation is admissible when evaluation of limited number of feasible solutions is desired (Črepinšek et al., 2013). Genetic Algorithm (GA) and Particle Swarm (PSO) algorithm have been applied to optimize of CCHP design and operational parameters. The PSO algorithm is used by Tichi et al. (2010) for minimizing the cost of operating various $\mathrm{CHP}$ and CCHP systems in an industrial dairy unit. Wu (2011) considered the optimisation of operation of a CHP system under uncertainty and used the PSO algorithm to solve the model. Ghaebi et al. (2012) investigated exergoeconomic optimisation of a CCHP system. The presented economic model was based on the Total Revenue Requirement (TRR) and the total cost of the system was defined as the objective function. This model was solved by GA. Designing CCHP systems involves determination of the equipment's capacity as the main goal. Wang et al. (2010) designed a CCHP system with consideration of PGU and storage tank capacity as decision variables. On-off coefficient and 
"electric cooling to cool load" ratio was considered as decision variables too. This research was extended by an investigation a biomass gasification CCHP system (Wang et al., 2014). In this research the capacity of the gasification reactor, PGU, absorption chiller, electric chiller, and heat exchanger were considered as decision variables. In another study by Sanaye et al. (2015) a CCHP system was designed with equipment's capacity, partial load of PGU in each month, and electric cooling to cool load ratio as decision variables. This study considered a more comprehensive design compared with previous studies; in addition to the capacity of PGU, the number of them was considered as the decision variables. When a high-capacity PGU is installed, due to fluctuations in electric demand, the optimum solution dictates that the PGU is in off state a number of courses. This will lead to purchase of the whole electricity demand from the grid and supplement of heating demand by auxiliary boiler. Therefore, energy consumption and pollution increase during these periods; also, the cost of buying electricity will increase significantly. Consequently, it might be more beneficial to consider a number of smaller-capacity PGU instead of a large-scale one. This is why the number of PGUs is considered as a decision variable.

In the previous research the number and the capacity of the equipment, the on-off coefficient, and "electric cooling to cool load ratio" under different strategies were not simultaneously considered as decision variables. Therefore, the interconnections between these variables have not been taken into account, which is investigated in this study. In this research various strategies, for simultaneous utilization of several power generation units and adaptation of the operation status of chillers throughout the year, are explored so that the performance of the system under different circumstances is evaluated. Commonly employed strategies such as Following Electrical Load (FEL) and Following Thermal Load (FTL) are implemented for an actual set of buildings to optimize the performance of the CCHP system. Moreover, different strategies are implemented for a real case and results are analysed. As mentioned before, main goal of using the CCHP systems is to lower the economic costs and the environmental consequences. In this study, it is endeavoured to reflect the influence of optimum design and operation planning of the system in reduction of economic costs, environmental footprint measured in terms of $\mathrm{CO}_{2}$ emissions, and energy consumption. As a summary, the followings are the contribution of this paper:

- Three commonly employed strategies in addition to two novel strategies for operational planning of CCHP systems are explored.

- GA and PSO algorithms are employed to obtain the optimum values of design parameters and their performance in solving this optimisation problem are compared.

- Eight design parameters (decision variables), including the capacity of gas turbine as the prime mover, their number and operational strategy, the capacity of the backup boiler and storage tank, the capacity of electrical and absorption chillers, the electric cooling ratio, and the on-off coefficient of PGUs are considered and the results under various strategies are compared.

- The developed strategies and algorithms are applied to a real case study.

\section{Problem Description}

Conventionally, in Separate Production (SP) systems, electric chillers are used to fulfil cooling demand, while heating demand of the buildings is supplied with a boiler (commonly a gas boiler), and the electricity is purchased off the grid. CCHP systems, however, consist of several separated segments that perform in an integrated fashion to fulfil the electricity, cooling, and heating demands. Fig. 1 shows general structure of a CCHP system. PGU generates electricity power by consuming the fuel; the heat exchanger retrieves heat generated during generation of electricity; depending on the implemented strategy, the recovered heat is either used to fulfil the heating demand or is directed to the absorption chiller to fulfil the cooling demand; the electric chiller is used to complement the absorption chillers and fulfil the cooling demand when needed; the auxiliary boiler and energy storage tank reduce the risk of system failure and increase system reliability. 


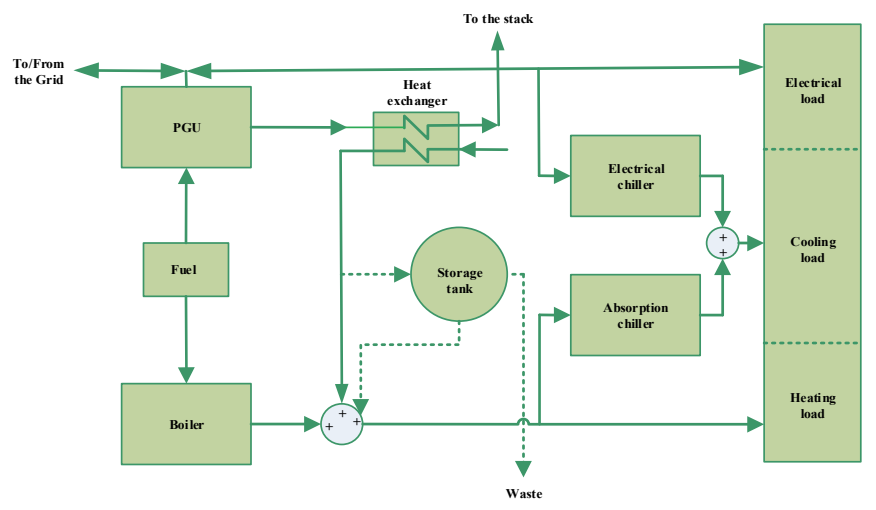

Fig. 1. Schematic of a CCHP system (Sanaye \& Hajabdollahi, 2015)

Operational planning of CCHP systems is usually conducted based on two strategies: FEL and FTL. The core of FEL strategy is fulfilment of the electrical demand. If the electrical demand of the buildings exceeds the capacity of PGU, it works in full load; otherwise it works in partial load to provide the required amount of electrical power. The cooling load provided by the electric chiller is determined in each period (an hour) based on the electrical power production. When systems operate based on FEL, overproduction of thermal energy would be wasted. When the energy generated by the PGU is insufficient, lack of electricity is purchased from the grid. Also, thermal storage tanks are used to enhance thermal efficiency of the CCHP systems. Recovered heat from the PGU will be used by the absorption chiller for cooling, or by the heat exchanger to supply the heat demand of the buildings.

On the contrary to the FEL strategy, in the FTL strategy, the purpose is to fulfil the thermal demand of the building, so there is no excess of thermal energy and in case of shortage, thermal energy would be supplied by an auxiliary boiler. When CCHP system operates based on the FTL, surplus or shortage of electrical power is possible. In case of surplus, if selling the excess electricity to the grid is not possible, surplus electricity would be wasted; and in case of shortage, unmet electricity demand is fulfilled by purchasing from the grid.

Another commonly adopted strategy for operational planning of CCHP systems is similar to FEL but with an additional decision variable $(x)$ which defines the ratio of electric cooling to cool load. In other words, in this strategy the proportion of the cooling demand supplied by the electric chiller is a decision variable, compared to the FEL strategy where the priority is always given to the electric chiller and the capacity of the PGU defines the amount of the cooling demand supplied by the electric chiller. Using FEL with no restriction on the electric chiller utilization might lead to significant heat waste which could have been used by the absorption chiller to supply the cooling demand. In order to prevent increasing the complexity of the model, the value of $x$ is commonly considered to be fixed throughout the year (Sanaye \& Khakpaay, 2014; J. Wang et al., 2010) (one decision variable is added instead of 8760 variables).

As mentioned before, using several smaller PGUs instead of a single large-capacity PGU could be beneficial in some cases. At the first glance, deployment of several PGUs will dramatically increase the capital cost of the system; however, the operational costs could be reduced to the extent that compensate the extra capital cost. Therefore, considering the multi-PGU case provides the opportunity to evaluate the trade-off between the higher capital cost and the reduced operational costs which is missed when a single PGU is considered. Specifically, under the FEL strategy, it is anticipated that multi-PGU approach offers more favourable results when the minimum and maximum electrical load of the system throughout the year are widely different. If the electric load fluctuations in the system is significant and we have a high capacity PGU, it will be turned off in many periods when the partial load would fall below its economical operational threshold (as explained in section 3.1) leading to higher purchased amount of the electricity from the grid and utilizing the auxiliary boiler to fulfil the heat demand. On the contrary when 
several PGUs are available their status (on/off) could be adjusted respective to the partial load of the system, hence, reducing the operational costs. Similarly, when using a single high-capacity PGU under the FTL strategy, in a number of periods during spring and fall the PGU is turned off because the heating demand of the system is reduced and the PGU must operate at a low partial load that is not economical (as explained in section 3.1). Having several PGU with smaller capacity could reduce purchasing power from the grid and reduce supplying heating demand by the auxiliary boiler, hence, improving system's performance. Considering several PGU will change how the operational strategies are applied. When using FEL strategy in a multi-PGU system, in order to determine the status (on/off) of each PGU at each time step, the PGUs are sorted based on their capacity and the smallest unit with the lowest capacity is placed in active status. The reminder of the electrical demand is assigned to the next PGU and it is activated. This is continued until the demand is fully responded or the generation of the electricity by the next PGU is not economically viable. This approach is expected to increase the efficiency of the PGUs by increasing their utilization rate. When using the FTL strategy, in order to determine the status (on/off) of each PGU, the PGUs are sorted based on their capacity and the smallest unit with the lowest capacity is placed in active status. The reminder of heating demand is assigned to the next PGU and it is activated. This is continued until the heating demand is fully responded or the activation of the next PGU is not economically viable.

\section{Model formulation}

In the followings, the parameters of the model are introduced and the objective functions and constraints are presented. Table 1 shows a list of the parameters and symbols used in the model.

Table 1

Parameters and symbols of the developed model

\begin{tabular}{|c|c|c|c|}
\hline \multicolumn{2}{|c|}{ Parameter } & \multicolumn{2}{|l|}{ Subscripts } \\
\hline$\eta_{r}$ & Heat recovery factor & $e$ & Electricity \\
\hline$\eta_{\text {grid }}$ & Transmission efficiency & $r$ & Recovery \\
\hline$\eta_{\text {plant }}$ & Plant efficiency & $f$ & Fuel \\
\hline$\eta_{s}$ & Heat storage efficiency & $h$ & Hour \\
\hline$i$ & Interest rate & temp & Temporary \\
\hline$n$ & Lifetime of the equipment (year) & nom & Nominal \\
\hline$C_{e, b u y}$ & Purchase price of the electricity $(\$ / \mathrm{kWh})$ & $p$ & Pumps and other equipment \\
\hline$C_{e, \text { sale }}$ & Selling price of the electricity $(\$ / \mathrm{kWh})$ & hea & Heating \\
\hline$C_{f, b}$ & Buying price of the fuel for boiler $(\$ / \mathrm{kWh})$ & $j$ & Number of PGU (counter) \\
\hline$C_{f, p g u}$ & Buying price of the fuel for PGU $(\$ / \mathrm{kWh})$ & $k$ & Equipment number (counter) \\
\hline$\mu_{c o 2_{e}}$ & $\mathrm{CO}_{2}$ emission of electricity $(\mathrm{gr} / \mathrm{kWh})$ & req & Required \\
\hline$\mu_{\mathrm{co}_{f}}$ & $\mathrm{CO}_{2}$ emission of fuel (gr/kWh) & $p g u$ & Power Generation Unit \\
\hline$E l$ & Electrical demand of the buildings $(\mathrm{kW})$ & $\max$ & Maximum capacity \\
\hline$Q_{c}$ & Cooling demand of the buildings $(\mathrm{kW})$ & $\min$ & Minimum capacity \\
\hline$Q_{\text {hea }}$ & Thermal demand of the building $(\mathrm{kW})$ & total & Total amount \\
\hline$C O P_{e c}$ & Coefficient of performance of electric chiller & best & The best amount \\
\hline$C O P_{a c}$ & $\begin{array}{l}\text { Coefficient of performance of absorption } \\
\text { chiller }\end{array}$ & symbols & \\
\hline$T a_{c}$ & Carbon tax $(\$ / \mathrm{kg})$ & $P L$ & Partial load \\
\hline
\end{tabular}




\begin{tabular}{llll}
\hline \multicolumn{2}{l}{ Subscripts } & $K$ & Total number of PGUs \\
out & Exit & $N$ & Total number of equipment \\
\hline in & Entrance & $C$ & Capital cost per $\mathrm{kW}(\$ / \mathrm{kW})$ \\
$E$ & Electricity Generated/Required & Cap & Capital cost of equipment $(\$)$ \\
$a c$ & Absorption chiller & $f r$ & Instantaneous fraction \\
\hline ec & Electric chiller & $x$ & Electric cooling to cool load ratio \\
\hline$c$ & Cooling & $Q$ & Heating load $(\mathrm{kW})$ \\
$b$ & Boiler & $F$ & Fuel consumption $(\mathrm{kWh})$ \\
\hline$S$ & Storage tank & $S l$ & Salvage value $(\$)$ \\
\hline grid & Local grid & & \\
\hline
\end{tabular}

\subsection{Under FEL strategy}

When FEL is the adopted strategy, the ratio of cooling load supplemented by the electric chiller per hour is calculated by (1). The amount of cooling load supplied by the electric chiller is calculated by (2).

$$
\begin{aligned}
& x_{h}= \begin{cases}1 & \text { if } E_{p g u, \text { max }} \geq E l_{h}+E_{p, h}+Q_{c, h} / C O P_{e c} \\
\left(\left(E_{p g u, \text { max }}-E l_{h}-E_{p, h}\right) \times C O P_{e c}\right) / Q_{c, h} & \text { if } E l_{h}+E_{p, h} \leq E_{p g u, \max }<E l_{h}+E_{p, h}+Q_{c, h} / C O P_{e c} \\
0 & \text { if } E_{p g u, \max }<E l_{h}+E_{p, h}\end{cases} \\
& Q_{e c, h}=x_{h} \cdot Q_{c, h}
\end{aligned}
$$

The electricity consumption of the electric chiller is calculated as shown in (3). The capacity constraint of the electric chiller is shown in (4). The total electricity requirement of buildings is shown in (5). The capacity utilization of the PGU is denoted by $f r_{p g u, h}$, called the instantaneous fraction of the PGU, and is calculated using (6).

$$
\begin{aligned}
& E_{e c, h}=Q_{e c, h} / C O P_{e c} \\
& Q_{e c, \min } \leq Q_{e c} \leq Q_{e c, \max } \\
& E_{r e q, h}=\left(E l_{h}+E_{p}\right)+E_{e c, h} \\
& f r_{p g u, h}=\frac{E_{r e q, h}}{E_{p g u, \max }}
\end{aligned}
$$

The efficiency of the PGU is highly dependent on its capacity utilization (Wang et al., 2011). Below a certain threshold it is not rational to use the PGU since most of the consumed fuel is wasted on heat generation rather than electricity generation. In (7), $\alpha$ is considered as the lower bound on the instantaneous fraction to ascertain the PGU is either turned off or is working above the predetermined level. $\alpha$ is a decision variable in the model and its upper limit is equal to 1 .

$$
E_{p g u, h}= \begin{cases}0 & \text { if } \quad f r_{p g u, h}<\alpha \\ E_{r e q, h} & \text { if } \quad \alpha \leq f r_{p g u, h}<1 \\ E_{p g u, \max } & \text { if } \quad f r_{p g u, h} \geq 1\end{cases}
$$

Partial load of PGU is calculated by (8. The efficiency of the PGU is determined by (9). Increasing the partial load of PGU increases its efficiency (Sanaye \& Hajabdollahi, 2013; Sanaye, Meybodi, \& Shokrollahi, 2008) as shown in the (9). The electricity purchased from the grid or sold to the grid is calculated using (10). 


$$
\begin{aligned}
& P L_{p g u, h}=\frac{E_{p g u, h}}{E_{p g u, \max }} \\
& \frac{\eta_{p g u, h}}{\eta_{p g u, n o m}}=-0.0001591\left(P L_{p g u, h}\right)^{2}+0.024\left(P L_{p g u, h}\right)+0.1904 \\
& E_{g r i d, h}=E_{h}+E_{p}+E_{e c, h}-E_{p g u, h}
\end{aligned}
$$

(11) declares that power exchange with the grid was purchase off the grid or sold to the grid. The fuel consumed by PGU is estimated by the (12). Based on the fuel consumption and the efficiency of the PGU, the generated heat is calculated by (13).

$$
\begin{gathered}
-u_{1, h} . E_{s a l e, h}+u_{2, h} E_{b u y, h}=E_{g r i d, h} \\
u_{1}+u_{2} \leq 1 \quad u_{1}, u_{2} \in\{0,1\} \\
F_{p g u, h}=\frac{E_{p g u, h}}{\eta_{p g u, h}} \\
Q_{p g u, h}=F_{p g u, h}\left(1-\eta_{p g u, h}\right)
\end{gathered}
$$

The amount of the recovered heat is calculated by (14). Fuel consumption related to the electricity purchased from the grid is calculated by (15). The supplied cooling via absorption chiller is determined by (16). Absorption chiller's cooling range is between minimum and the maximum capacity of absorption chiller, represented in (17).

$$
\begin{aligned}
& Q_{r, h}=Q_{p g u, h} \cdot \eta_{r} \\
& F_{e, h}=\frac{E_{b u y, h}}{\eta_{g r i d} \times \eta_{p l a n t}} \\
& Q_{a c, h}=\left(1-x_{h}\right) \cdot Q_{c, h} \\
& Q_{a c, \text { min }} \leq Q_{a c, h} \leq Q_{a c, \max }
\end{aligned}
$$

The heat consumed by the absorption chiller is calculated by its coefficient of performance in (18). The total amount of heat requirement of the system is calculated as (19).

$$
\begin{aligned}
& Q_{a c, i n, h}=\left(1-x_{h}\right) \times Q_{c, h} / C O P_{a c} \\
& Q_{r e q, h}=Q_{a c, i n, h}+Q_{h e a, h}
\end{aligned}
$$

Part of the heat requirement is supplied by recovered heat from the PGU and the rest is provided by the backup boiler. The generated heat from the auxiliary boiler can be calculated by (20). Capacity constraint of the boiler is represented in (21). Partial load of the boiler is determined by (22) and its efficiency can be calculated by (23) (Sanaye \& Hajabdollahi, 2013; Sanaye et al., 2008).

$$
\begin{aligned}
& Q_{b, h}=\left\{\begin{array}{lll}
0 & \text { if } & Q_{r, h}+Q_{s, h}-Q_{r e q, h} \geq 0 \\
Q_{r e q, h}-Q_{r, h}-Q_{s, h} & \text { if } & Q_{r e q, h}-Q_{r, h}-Q_{s, h}>0
\end{array}\right. \\
& Q_{b, \min } \leq Q_{b, h} \leq Q_{b, \max } \\
& P L_{b, h}=\frac{Q_{b, h}}{Q_{b, \max }} \\
& \frac{\eta_{b, h}}{\eta_{b, \text { nom }}}=0.0951+1.525\left(P L_{b, h}\right)-0.6249\left(P L_{b, h}\right)^{2}
\end{aligned}
$$


Fuel consumption of the auxiliary boiler is calculated by (24) and the total fuel consumption in the CCHP system is determined in (25). The amount of heat charged in or discharged from storage tank can be determined by (26). The initial investment cost per $\mathrm{kW}$ capacity of equipment $(\$ / \mathrm{kW})$ is determined using (27) and (28) (Sanaye \& Hajabdollahi, 2013).

$$
\begin{aligned}
& F_{b, h}=\frac{Q_{b, h}}{\eta_{b, h}} \\
& F_{h}=F_{b, h}+F_{p g u, h} \\
& Q_{h+1, s}=\eta_{s} \cdot Q_{h, s}+U_{h, s, i n} \cdot Q_{h, s, \text { in }}-U_{h, s, \text { out }} \cdot Q_{h, s, \text { out }} \\
& U_{h, s, \text { in }} \& U_{h, s, \text { out }} \in\{0,1\} \\
& U_{h, s, \text { in }}+U_{h, s, \text { out }} \leq 1 \\
& C_{1}=-0.014 \times 10^{-6} \times E_{p g u, \text { max }}+600 \\
& \text { Cap }_{1}=C_{1} \times E_{p g u, \text { max }}
\end{aligned}
$$

The gas turbine maintenance cost $(\$ / \mathrm{kW})$, expressed based on its capacity, is assumed equal to $\$ 0.0055$ $\mathrm{kWh}$ (Smith et al., 2010). The initial cost per kW of the boiler $(\$ / \mathrm{kW})$ is estimated by $(29$ and its total capital cost is calculated by (30. Operating cost of the boiler is assumed $\$ 0.0027 \mathrm{kWh}$ (Sanaye \& Hajabdollahi, 2013). Initial investment per $\mathrm{kW}(\$ / \mathrm{kW})$ of absorption and electric chiller are estimated as shown in (31 and (32, respectively (Sanaye et al., 2008). Their total capital cost is calculated by (33 and (34. Operating cost for both chillers is assumed to be $0.003 \$ / \mathrm{kWh}$ (Sanaye \& Hajabdollahi, 2013). The initial cost of a storage tank per $\mathrm{kW}$ is considered $33 \$ / \mathrm{kW}$ (Sanaye \& Hajabdollahi, 2013) so the total capital cost of storage tank is calculated by $(35$.

$$
\begin{aligned}
& C_{2}=205\left(Q_{b, \text { max }} \times 10^{-6}\right)^{-0.13} \\
& \text { Cap }_{2}=C_{2} \times Q_{b, \text { max }} \\
& C_{3}=540\left(Q_{a b, \text { max }} \times 10^{-6}\right)^{-0.128} \\
& C_{4}=482\left(Q_{c c, \text { max }} \times 10^{-6}\right)^{-0.07273}-159.7 \\
& \text { Cap }_{3}=C_{3} \times Q_{a b, \text { max }} \\
& \text { Cap }_{4}=C_{4} \times Q_{\mathrm{ec}, \text { max }} \\
& \text { Cap }_{5}=33 \times Q_{\mathrm{s}, \text { max }}
\end{aligned}
$$

\subsection{Under FTL strategy}

For the FTL strategy mathematical relationships are similar to FEL except for the chiller's operation parameters that are determined in a different way. At first the efficiency of PGU at full load $\left(\eta_{p g u, \max }\right)$ is calculated using (9) and the heat generated by the PGU is calculated by (36). Using the heat recovery factor, recovered heat from the CCHP system at the highest capacity is calculated in (37) and the ratio of electric cooling load to cool load is determined as shown in (38).

$$
\begin{aligned}
& Q_{p g u, \text { max }}=F_{p g u, h}\left(1-\eta_{p g u, h}\right)=\frac{E_{p g u, \max }}{\eta_{p g u, \max }}\left(1-\eta_{p g u, \text { max }}\right) \\
& Q_{r, \text { max }}=Q_{p g u, \text { max }} \cdot \eta_{r} \\
& x_{h}= \begin{cases}0 & \text { if } Q_{\mathrm{r}, \text { max }} \geq Q_{h e a, h}+Q_{c, h} / C O P_{a c} \\
1-\left(\left(Q_{\mathrm{r}, \max }-Q_{\text {hea }, h}\right) \times C O P_{a c}\right) / Q_{c, h} & \text { if } Q_{h e a, h}<Q_{\mathrm{r}, \max }<Q_{h e a, h}+Q_{c, h} / C O P_{a c} \\
1 & \text { if } Q_{\mathrm{r}, \max } \leq Q_{\text {hea }, h}\end{cases}
\end{aligned}
$$


By determination of $x_{h}$, the required heat can be calculated according to (19). If the required heat is less than $Q_{r, \max }$, recovered heat would be equal to its required heat. By using (39), $E_{p g u, h, t e m p}$ is calculated and using (40 temporary partial load $\left(P L_{\text {pgu,h,temp }}\right)$ is calculated. As shown in $(41), d_{h}$ is a binary variable which equals to 1 when PGU is on and equals to zero when PGU is off. Using (42), heat recovered from the PGU is calculated based on heat requirement of the system. Based on the recovered heat of PGU the amount of electrical generation $\left(E_{p g u, h}\right)$ is estimated and the partial load of PGU is calculated by (43). In other words, at first $P L_{p g u, h, t e m p}$ is calculated to determine if PGU should be in on or off mode. After determination of PGU's state, the amount of $P L_{p g u, h}$ is calculated.

$$
\begin{aligned}
& E_{p g u, h, t e m p}=\frac{Q_{r e q, h} \cdot \eta_{p g u, h}}{\left(1-\eta_{p g u, h}\right) \eta_{r}} \\
& P L_{p g u, h, \text { temp }}=\frac{E_{p g u, h, t e m p}}{E_{p g u, \max }} \\
& d_{h}=\min \left\{\left\{\frac{P L_{p g u, h, t e m p}}{\alpha}\right], 1\right\} \\
& Q_{\text {rec }, h}= \begin{cases}Q_{\text {rec }, \text { max }} & \text { if } Q_{\text {req }, h} \geq Q_{\text {rec }, \text { max }} \\
d_{h} \times Q_{\text {req }, h} & \text { otherwise }\end{cases} \\
& P L_{p g u, j, h}=\frac{E_{p g u, j, h}}{E_{p g u, j, \max }}
\end{aligned}
$$

\subsection{Under FEL strategy with fixed ratio of electric cooling to cool load}

As previously mentioned, in the third strategy, the ratio of electric cooling to cool load is considered as a decision variable. PGU operates based on FEL but $x$ is determined on the basis of both electrical and thermal load and Eq. (1) is omitted from the optimisation model.

\subsection{Multiple PGUs, Under FEL strategy with fixed ratio of electric cooling to cool load}

The power generation for each of the PGUs in each period of time is calculated in (7) until condition $f_{p g u, h}<\alpha$ is met. By this condition the other units will become inactive. PGUs are sorted in descending order of $E_{p g u, \max }$ as shown in (44). In this stage, based on FEL strategy the total electrical requirement of the system is determined. Total electricity requirement for each unit can then be calculated by (45) and (46). Initially the instantaneous load factor of the active unit is calculated in (47); then, the amount of electricity generated for each active unit is determined using (48).

$$
\begin{aligned}
& E_{p g u, j, \max } \leq E_{p g u, j+1, \max } \quad j \in\{1, \ldots, \mathrm{K}-1\} \\
& E_{r e q, 1, h}=E_{r e q, h} \\
& E_{r e q, j+1, h}=E_{r e q, j, h}-E_{p g u, j, h} \quad j \in\{1, \ldots, \mathrm{K}-1\} \\
& f r_{p g u, j, h}=\frac{E_{r e q, j, h}}{E_{p g u, j, \max }} \\
& E_{p g u, j, h}=\left\{\begin{array}{lll}
0 & \text { if } & f r_{p g u, j, h}<\alpha \\
E_{r e q, j, h} & \text { if } & \alpha \leq f r_{p g u, j, h}<1 \\
E_{p g u, j, \max } & \text { if } & f r_{p g u, j, h} \geq 1
\end{array}\right.
\end{aligned}
$$


At this stage, the electricity generated by the CCHP system in each period is determined. If unit number $j$ is placed on inactive status all next units will be in inactive status. This restriction is shown in (49); then, the total electrical load production is calculated by (50). (49) shows that PGUs are activated respectively and (50) represents total electricity generated by PGUs. Purchased electricity from the grid can be calculated by (51). Calculation of total heat retrieved from the CCHP system in each period is based on (52). The rest of the equations are similar to FEL strategy.

$$
\begin{aligned}
& \gamma_{j+1} \leq \gamma_{j} \quad j \in\{1,2, \ldots, K-1\} \quad \gamma_{j} \in\{0,1\} \\
& E_{\text {total }, p g u, h}=\sum_{j=1}^{K} \gamma_{j} \times E_{p g u, j, h} \\
& E_{\text {grid }, h}=E_{r e q, \mathrm{~K}, h}-E_{p g u, \mathrm{~K}, h} \\
& Q_{\text {rec }, h}=\sum_{j=1}^{K} Q_{r e c, j, h}
\end{aligned}
$$

\subsection{Multiple PGUs, under FTL strategy with fixed ratio of electric cooling to cool load}

(49 is used to sort the PGUs. First, the entire heating system requirement is determined by (19). For the first activated unit the total heating demand of the system is considered as the required heat amount which is shown in (53). By (54) required heat of other units can be determined. After the last PGU, if still there is unmet demand, the auxiliary boiler is used for which the amount of heating demand is calculated using (55).

$$
\begin{aligned}
& Q_{r e q, 1, h}=Q_{r e q, \mathrm{~h}} \\
& Q_{\text {req }, j+1, h}=Q_{r e q, j, h}-Q_{r e c, j, h} \quad j \in\{1,2, \ldots, K-1\} \\
& Q_{\text {boiler }, h}=Q_{r e q, \mathrm{~K}, h}-Q_{r e c, \mathrm{~K}, h}
\end{aligned}
$$

\subsection{Evaluation Criteria}

Capital and variable costs, the amount of $\mathrm{CO}_{2}$ emissions, and amount of energy consumption are considered as the criteria in the objective function in the optimisation model. The first criterion evaluates the economic costs of the system. It consists of the capital cost of equipment, cost of fuel consumed by the boiler and the PGU, operation cost of equipment, and cost/profit from transfer of electricity from/to the grid. Salvage value of equipment is considered 10\% of their capital cost (Gibson et al., 2015).

$$
\begin{aligned}
& R=\frac{i(1+i)^{n}}{(1+i)^{n}-1} \\
& A=\frac{i}{\left((1+i)^{n}-1\right)} \\
& Z_{1}=A T C=R \times\left[\sum_{k=1}^{N} C_{k} \times C a p_{k}\right]-A \times S l+\sum_{h=1}^{8760}\left(E_{b u y, h} . C_{e, b u y}+F_{b, h} \cdot C_{f, b}+F_{p g u, h} \cdot C_{f, p g u}-E_{\text {sale }, h} C_{e, \text { sale }}\right. \\
& \left.+0.0055 \times E_{p g u, h}+0.0027 \times Q_{b, h}+0.003 \times Q_{c, h}\right)-T a_{c} \times 10^{-3} \times C D E \\
& Z_{2}=C D E=\sum_{h=1}^{8760} \mu_{c 2_{f}} \cdot F_{h}+\mu_{c o 2_{e}} \cdot E_{b u y, h}
\end{aligned}
$$

$R$ is the capital recovery factor and calculated as shown in (56 and $A$ is the uniform series sinking fund and its value is calculated using (57), $n$ represents the service life of the equipment and $i$ is the interest rate. Similar to Bahrami and Farahbakhsh (2013), it is assumed that the values of $i$ and $n$ are equal for all 
equipment. The Annual Total Cost (ATC) is calculated by (58. The second criterion evaluate the amount of $\mathrm{CO}_{2}$ Emissions (CDE) to reflect environmental concerns. $\mathrm{CO}_{2}$ emissions are released by fuel consumption of auxiliary boiler and the PGU. Also, when electricity is purchased from the grid, the related $\mathrm{CO}_{2}$ emissions are accounted for as shown in (59).

The third criterion represents the Primary Energy Consumption (PEC) of the system which is composed of two parts. The first part is amount of fuel consumed by the boiler and the PGU, and the second part is the fuel related to the electrical energy purchased from the grid. Total energy consumption of the system is shown in (60). In this study we use a weighted sum of these three criterion to form a single objective function as shown in (61).

$$
\begin{aligned}
& Z_{3}=P E C=\sum_{h=1}^{8760} F_{h}+F_{e, h} \\
& \min Z=\omega_{1} \frac{Z_{1}}{Z_{1, \text { best }}}+\omega_{2} \frac{Z_{2}}{Z_{2, \text { best }}}+\omega_{3} \frac{Z_{3}}{Z_{3, \text { best }}}
\end{aligned}
$$

To calculate the optimal value of the multi objective function, first each of the single-objective functions are optimised to obtain the optimum value for each of them, denoted as $Z_{1, \text { best }}, Z_{2, \text { best }}$, and $Z_{3, \text { best }}$ in (61. Each single-objective function is normalized and then sum of them is calculated. By changing the weights different results can be achieved. Since the economic cost of fuel consumption (fuel consumption of the PGU, boiler and electricity purchased from the grid) in CCHP system in addition to $\mathrm{CO}_{2}$ tax are considered in ATC function, the objective functions are largely aligned with each other which makes using the normalized weighted sum a proper method in handling the multi-objective optimisation model.

\section{Evolutionary Algorithms}

GA and PSO are both population-based algorithms commonly employed in the field of energy planning. Genetic algorithm was introduced by John Holland (Mitchell, 1998) as an evolutionary algorithm inspired by biology concepts such as inheritance, mutation, selection and crossover. Small random changes are determined by mutation which is determinative of GA diversity. Crossover operator determines how the algorithm combines two selected parents, to generate children for the next generation. Candidate solutions are assessed by the evaluation function (also known as fitness function).

PSO was invented by Kennedy and Eberhart in the mid1990s (1995), inspired by the movement of the particles. The PSO algorithm includes three phases, namely, generating particles' positions and velocities, updating the velocity of particles, and updating the position of particles. The three values that affect the new direction of a particle are its current motion, the best position in its memory, and swarm influence. (62) shows how the movement speed of the particle is updated and (63) shows how the new position of the particle is determined where the inertia coefficient for particle $i$ in its next movement is represented by $v^{i}[t+1]$, new position of the particle $i$ is represented $x^{i}[t+1]$, and $w$ is the current motion factor, $c_{1}$ is particle own memory factor, and $c_{2}$ is the swarm influence factor.

$$
\begin{aligned}
& v^{i}[t+1]=w v^{i}[t]+c_{1} r_{1}\left(x^{i, b e s t}[t]-x^{i}[t]\right)+c_{2} r_{2}\left(x^{g b e s t}[t]-x^{i}[t]\right) \\
& x^{i}[t+1]=x^{i}[t]+v^{i}[t+1]
\end{aligned}
$$

\subsection{Solution Representation}

Solution representation scheme adopted in this research are similar for the both algorithms, with minor differences respective to the implemented strategy. In GA, a chromosome is a set of parameters which define a solution for the problem. An example chromosome for each strategy is shown Fig. 2. In the FEL strategy a chromosome with six bits is used. Chromosomes encompass normalized variables, i.e., all the bits filled with continuous variables between zero and one. Bits represent the capacity of PGU, auxiliary boiler, absorption chillers, electric chiller, heating storage tank and on/off coefficient. In the FTL strategy 
chromosome consist of 5 bits. In this strategy chromosome structure is similar to the FEL strategy just the bit corresponding to heat storage tank capacity is removed, because in this strategy excess heat is not produced at any time and thus the storage tank is removed. In FEL with fixed ratio of electric cooling load to cool load the chromosome has one bit more than in the FEL strategy which is related to the electric cooling load to cool load ratio. In the multi-PGUs strategy an upper limit for the number of PGUs is considered and binary bits are used to indicate the instalment of the PGUs; corresponding to each binary bit there is one bit related to that PGU's capacity. Therefore, assuming $n$ as the upper limit on the number of the PGUs, $2^{*} n$ bits are considered for PGUs to determine their instalment and capacity.

\begin{tabular}{|c|c|c|c|c|c|}
\hline \multicolumn{6}{|c|}{ FEL Strategy } \\
\hline 1 & 2 & 3 & 4 & 5 & 6 \\
\hline \multicolumn{6}{|c|}{ 1: PGU Capacity } \\
\hline \multicolumn{6}{|c|}{ 2: Boiler Capacity } \\
\hline \multicolumn{6}{|c|}{ 3: Electric chiller Capacity } \\
\hline \multicolumn{6}{|c|}{ 4: Absorption Chiller Capacity } \\
\hline \multicolumn{6}{|c|}{ 5: Storage Tank Capacity } \\
\hline \multicolumn{6}{|c|}{ 6: On/Off Coefficient } \\
\hline
\end{tabular}

\begin{tabular}{|c|c|c|c|c|}
\hline \multicolumn{5}{|c|}{ FTL Strategy } \\
\hline 1 & 2 & 3 & 4 & 5 \\
\hline \multicolumn{5}{|c|}{ 1: PGU Capacity } \\
\hline \multicolumn{5}{|c|}{ 2: Boiler Capacity } \\
\hline \multicolumn{5}{|c|}{ 3: Electric chiller Capacity } \\
\hline \multicolumn{5}{|c|}{ 4: Absorption Chiller Capacit) } \\
\hline \multicolumn{5}{|c|}{ 5: On/Off Coefficient } \\
\hline
\end{tabular}

FEL Strategy under Fixed Ratio of Chillers

\begin{tabular}{|c|c|c|c|c|c|c|}
\hline 1 & 2 & 3 & 4 & 5 & 6 & 7 \\
\hline \multicolumn{7}{|c|}{ 1: PGU Capacity } \\
\hline \multicolumn{7}{|c|}{ 2: Boiler Capacity } \\
\hline \multicolumn{7}{|c|}{ 3: Electric chiller Capacity } \\
\hline \multicolumn{7}{|c|}{ 4: Absorption Chiller Capacity } \\
\hline \multicolumn{7}{|c|}{ 5: Storage Tank Capacity } \\
\hline \multicolumn{7}{|c|}{ 6: On/Off Coefficient } \\
\hline
\end{tabular}

FEL Multiple PGU Strategy under Fixed Ratio of Chillers

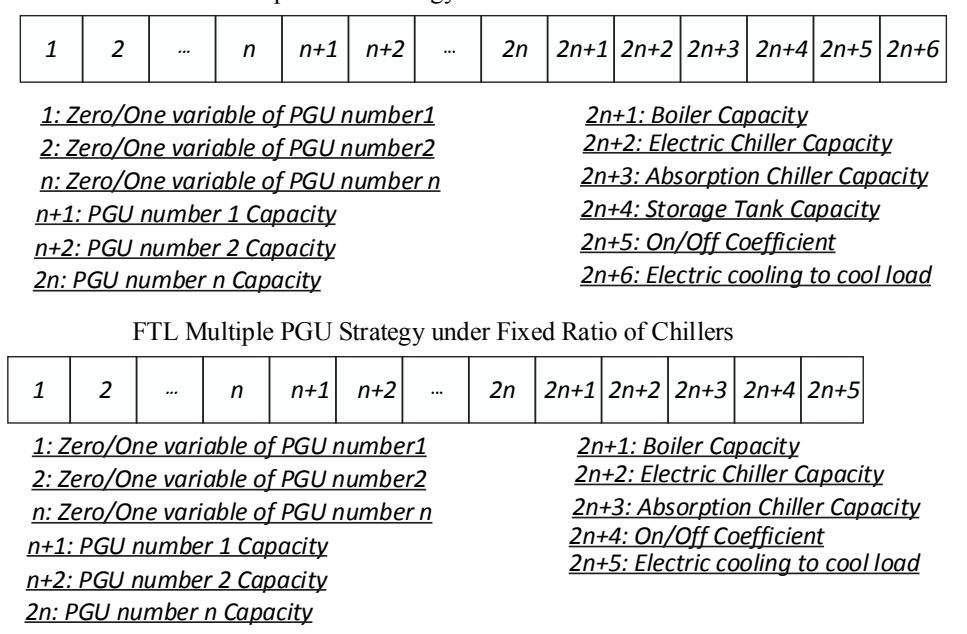

Fig. 2. Chromosomes in different strategies

\subsection{Operators}

Mutation and crossover are the two essential operators in GA. In crossover operator, at first the parent chromosomes are selected, then by selection of genes from the parents, new off-springs are created. Parent chromosomes are selected according to their fitness; chromosomes which have better fitness function value have higher chance of being selected. After crossover, mutation takes place which prevents algorithm from premature convergence to a local optimum by inserting randomly created solutions based on the existing ones. In Fig. 3 examples of crossover and mutation operators for FEL strategy are shown. In this study a single point crossover is implemented. The crossover point is randomly selected, and two new solutions are created by swapping the two sides of the point in the parents to form a new solution. Applying the mutation operator, two points of a given chromosome are randomly selected and swapped to form a new solution. An example of crossover and mutation operators for Muti-PGUs strategy is shown in Fig. 4. These chromosomes possess binary and continues variables limited to $[0,1]$. Crossover operator is exactly the same for the multi-PGU strategy.

To apply mutation two random points are selected. If this selected point is binary, the bit will change to its contrary form. The capacity related to this binary variable will change based on this bit's new value. For example, if it becomes zero the capacity related to this bit will change to zero; otherwise the capacity 
related to this bit is updated to a new random value. If selected bit is continuous, it will become updated to a new continuous random variable by mutation operator.

In the implemented PSO algorithm the particles structure is similar to the chromosome structure in GA. Mutation is the only operator in PSO which is same as GA.

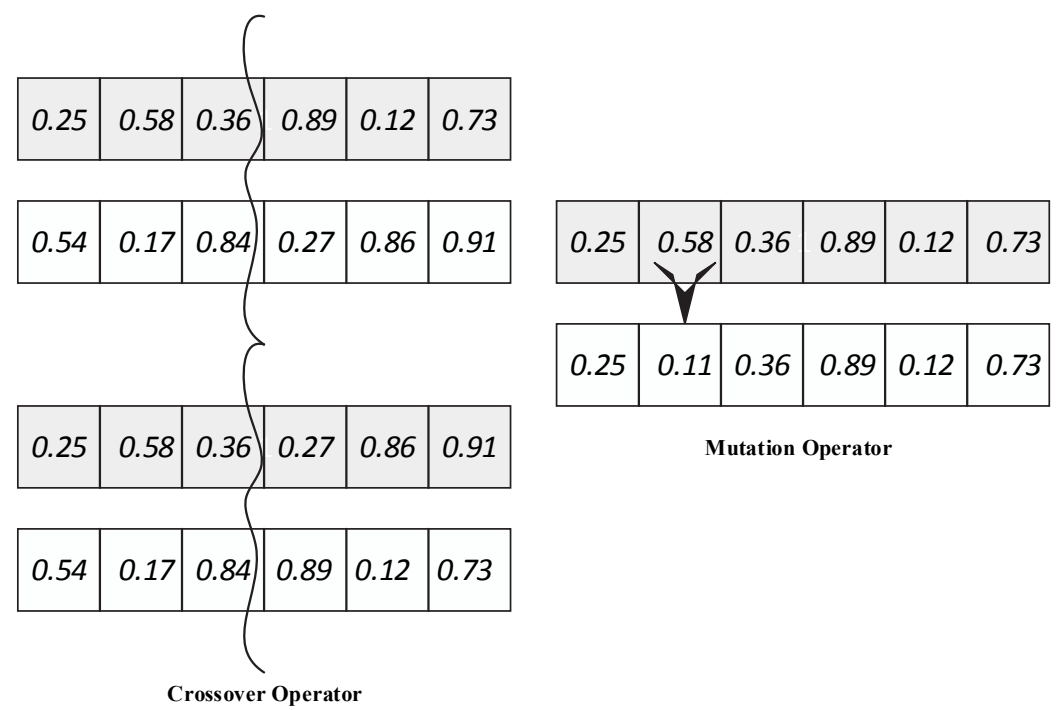

Fig. 3. Mutation and crossover example of FEL

\begin{tabular}{|c|c|c|c|c|c|c|c|c|c|c|c|c|c|c|c|}
\hline 1 & 1 & 1 & 0 & 0 & 0.37 & 0.17 & 0.14 & 0 & 0 & 0.15 & 0.86 & 0.28 & 0.67 & 0.27 & 0.07 \\
\hline 1 & 1 & 0 & 0 & 0 & 0.84 & 0.42 & 0 & 0 & 0 & 0.65 & 0.81 & 0.96 & 0.63 & 0.10 & 0.67 \\
\hline 1 & 1 & 0 & 0 & 0 & 0.37 & 0.17 & 0 & 0 & 0 & 0.65 & 0.81 & 0.96 & 0.63 & 0.10 & 0.67 \\
\hline 1 & 1 & 1 & 0 & 0 & 0.84 & 0.42 & 0.14 & 0 & 0 & 0.15 & 0.86 & 0.28 & 0.67 & 0.27 & 0.07 \\
\hline
\end{tabular}

\begin{tabular}{|l|l|l|l|l|l|l|l|l|l|l|l|l|l|l|l|}
\hline 1 & 1 & 1 & 0 & 0 & 0.37 & 0.17 & 0.14 & 0 & 0 & 0.15 & 0.86 & 0.28 & 0.67 & 0.27 & 0.07 \\
\hline
\end{tabular}
\begin{tabular}{|l|l|l|l|l|l|l|l|l|l|l|l|l|l|l|l|}
\hline 1 & 1 & 0 & 0 & 0 & 0.37 & 0.17 & 0 & 0 & 0 & 0.15 & 0.49 & 0.28 & 0.67 & 0.27 & 0.07 \\
\hline
\end{tabular}

Mutation Operator

Fig. 4. Crossover and mutation example of Multi-PGU

\section{Case study}

The proposed CCHP optimisation model and the solution procedures are applied to a real case study, an educational complex located in Mazandaran, Iran. The CCHP system provides electricity, heating (for 
both space heating and domestic hot water), and cooling. List of existing buildings, the total area of outer wall, windows, doors and usable area are shown in Table 2.

\section{Table 2}

List of existing buildings and their characteristics

\begin{tabular}{llllll}
\hline Type of building & Buildings number & Outer wall area & Windows area & Doors area & Usable area \\
\hline Common Villa & 40 & 6,102 & 644 & 31 & 8,817 \\
VIP villa & 28 & 576.5 & 89 & 34 & $1,150.5$ \\
Guest house & 77 & 299 & 25 & 63 & 315 \\
Restaurant & 3 & 882 & 127 & 32 & 1,100 \\
Residential building & 8 & 245.5 & 46.5 & 7 & 371 \\
Market & 1 & 334 & 104 & 66 & 504 \\
Mechanic Laboratory & 1 & 560 & 111.7 & 10.25 & 1,233 \\
Electric Laboratory & 1 & 568 & 169.7 & 7 & 1,225 \\
Educational sites & 2 & 822 & 118.2 & 33.6 & 2,951 \\
Sport hall & 1 & 1,454 & 142 & 15.5 & 1,609 \\
Central Kitchen & 1 & 644 & & 17.7 & 1,356 \\
\hline
\end{tabular}

The technical parameters of CCHP system and the specifications of the components are listed in Table 3. Design parameters (decision variables) and the acceptable range of their variations are listed in Table 4. The range of the decision variables is determined by load demand of the buildings; the range of the boiler and storage tank capacity are determined according to heating demand; and chillers capacity range is determined according to cooling demand of the buildings.

Table 3

Technical parameters and specifications of components

\begin{tabular}{|c|c|c|c|}
\hline Parameter & Explanation & Value & Reference \\
\hline$\eta_{r}$ & Heat recovery factor & 0.8 & (Wang \& Fang, 2011) \\
\hline$\eta_{\text {grid }}$ & Transmission Efficiency & 0.9 & (Iranian Electricity management, 2016) \\
\hline$\eta_{\text {plant }}$ & Plant Efficiency & 0.37 & (Iranian Electricity management, 2016) \\
\hline$\eta_{s}$ & Heat Storage Efficiency & 0.9 & (Iranian Fuel Conservation Organization, 2016) \\
\hline$\eta_{b, \text { nom }}$ & Max Efficiency of boiler & 0.8 & (Liu et al., 2013) \\
\hline$\eta_{p g u, \text { nom }}$ & Max Efficiency of PGU & 0.4 & (Iranian Electricity management, 2016) \\
\hline$i$ & Interest rate & 0.12 & (Ghaebi et al., 2012) \\
\hline$n$ & Lifetime of the equipment & 15 & (Q. Wang \& Fang, 2011) \\
\hline$S l$ & Salvage value & 0.1 & (Gibson et al., 2015) \\
\hline$C_{e, b u y}(\$ / \mathrm{kWh})$ & Purchase price of electricity & 0.12 & (Iranian Electricity management, 2016) \\
\hline$C_{e, s a l e}(\$ / \mathrm{kWh})$ & Selling price of electricity & 0.09 & (Iranian Electricity management, 2016) \\
\hline$C_{f, b}(\$ / \mathrm{kWh})$ & Buying price of gas for boiler & 0.04 & (Iranian Fuel Conservation Organization, 2016) \\
\hline$C_{f, p g u}(\$ / \mathrm{kWh})$ & Buying price of gas for $\mathrm{PGU}$ & 0.03 & (Iranian Fuel Conservation Organization, 2016) \\
\hline$\mu_{\mathrm{Co2}_{e}}(\mathrm{gr} / \mathrm{kWh})$ & Pollution emission of electricity & 968 & (Liu et al., 2013) \\
\hline$\mu_{c o 2_{f}}(\mathrm{gr} / \mathrm{kWh})$ & Pollution emission of fuel & 220 & (Liu et al., 2013) \\
\hline$T a_{c}(\$ / k g)$ & The carbon tax & 0.03 & (Liu et al., 2013) \\
\hline $\mathrm{COP}_{e c}$ & Coefficient of performance of electric chiller & 3 & (Liu et al., 2013) \\
\hline$C O P_{a c}$ & Coefficient of performance of absorption chiller & 0.7 & (Liu et al., 2013) \\
\hline
\end{tabular}


Table 4

Range of variations of the decision variables.

\begin{tabular}{ll} 
number of prime movers & $1-5$ \\
Nominal power range of prime movers & $500-5000$ \\
the on-off coefficient of PGU & $0.2-1$ \\
Boiler heating capacity & $100-6000$ \\
Electrical chiller cooling capacity & $100-4000$ \\
Absorption chiller cooling capacity & $100-4000$ \\
Electric cooling ratio & $0-1$ \\
Storage tank heating capacity & $0-5000$ \\
\hline
\end{tabular}

The electricity, cooling, and heating load curves are estimated using Energy Plus ("Energy Plus ", 2014) shown in Fig. 5.

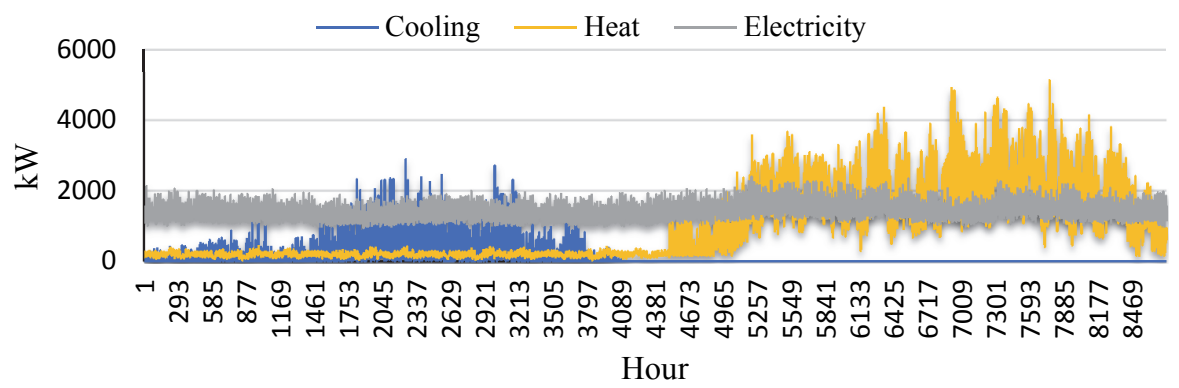

Fig. 5. Electricity, Cooling, and Heating load curves during a year

\section{Results and discussions}

In this section the results of the algorithms under each strategy is presented and the comparison is drawn between them. In this research GA and PSO are coded in MATLAB R $2013 b$ ("MATLAB," 2013) Stopping criteria and parameters for GA and PSO are represented in Table 5.

\section{Table 5}

Parameters for GA and PSO

\begin{tabular}{ll}
\hline Variable & Value \\
\hline GA & \\
\hline Population size & 100 \\
Maximum iteration number & 200 \\
Crossover probability & 0.6 \\
Mutation probability & 0.4 \\
\hline PSO & \\
\hline Population size & 100 \\
Maximum iteration number & 200 \\
Inertia weight $w$ & 0.9 \\
Particle own memory factor $C_{1}$ & 2 \\
Swarm influence factor $C_{2}$ & 2 \\
\hline
\end{tabular}




\subsection{Results for different strategies for different weights}

The results obtained when different weights for each objective function is used are shown in Fig. 6; 19 different weights results are represented. It is started by the $(1,0,0)$ vector and ended to $(0,0,1)$ vector for different scenarios. Extreme points which are related to single objectives are represented in Table 6; since minimizing $\mathrm{PEC}$ is equivalent to minimizing $\mathrm{CDE}$, only one row (under each strategy) is considered for these two objectives. As ATC decreases, PEC and CDE increase because investment decreases and less electricity is generated by the CCHP system. As a result, buying electricity from the grid increases rising PED and CED. PEC and CDE are aligned because consumption of more fuel consequences more emission. The range of the results for the three objectives is less than $1 \%$ because of the relationship between the objective functions, reaffirming the suitability of the using the weighted-sum method to handle the three objectives simultaneously. The equal weights method is implemented in many decisionmaking problems; this method's results are most of the time close to the optimal weighting methods as discussed in (Wang et al., 2009, 2010). Therefore, in the following all of weights are assumed equal and $w_{1}=w_{2}=\mathrm{w}_{3}=\frac{1}{3}$.

Table 6

$\underline{\text { Results of different strategies in thresholds }}$

\begin{tabular}{|c|c|c|c|c|c|c|}
\hline \multicolumn{3}{|c|}{ FEL } & \multicolumn{3}{|c|}{ FTL } & \multirow{2}{*}{ Weights } \\
\hline $\mathrm{TC}$ & $\mathrm{CDE}$ & PEC & $\mathrm{TC}$ & $\mathrm{CDE}$ & PEC & \\
\hline $2,617,692$ & $9,119,994,819$ & $41,210,138$ & $3,180,603$ & $15,542,546,552$ & $59,642,749$ & {$[1,0,0]$} \\
\hline $2,617,714$ & $9,115,345,992$ & $40,954,988$ & $3,181,048$ & $15,533,221,024$ & $59,571,263$ & $\begin{array}{l}{[0,0,1]} \\
{[0,1,0]}\end{array}$ \\
\hline \multicolumn{3}{|c|}{ FEL. Fixed ratio of cooling load } & \multicolumn{3}{|c|}{ Multiple PGU.FTL } & Weights \\
\hline $\mathrm{TC}$ & $\mathrm{CDE}$ & PEC & $\mathrm{TC}$ & $\mathrm{CDE}$ & PEC & \\
\hline $2,614,252$ & $9,021,807,496$ & $40,145,361$ & $1,826,494$ & $10,913,736,182$ & $41,285,055$ & {$[1,0,0]$} \\
\hline $2,614,514$ & $9,007,103,652$ & $40,020,287$ & $1,826,585$ & $10,910,462,062$ & $41,158,490$ & $\begin{array}{l}{[0,0,1]} \\
{[0,1,0]}\end{array}$ \\
\hline
\end{tabular}

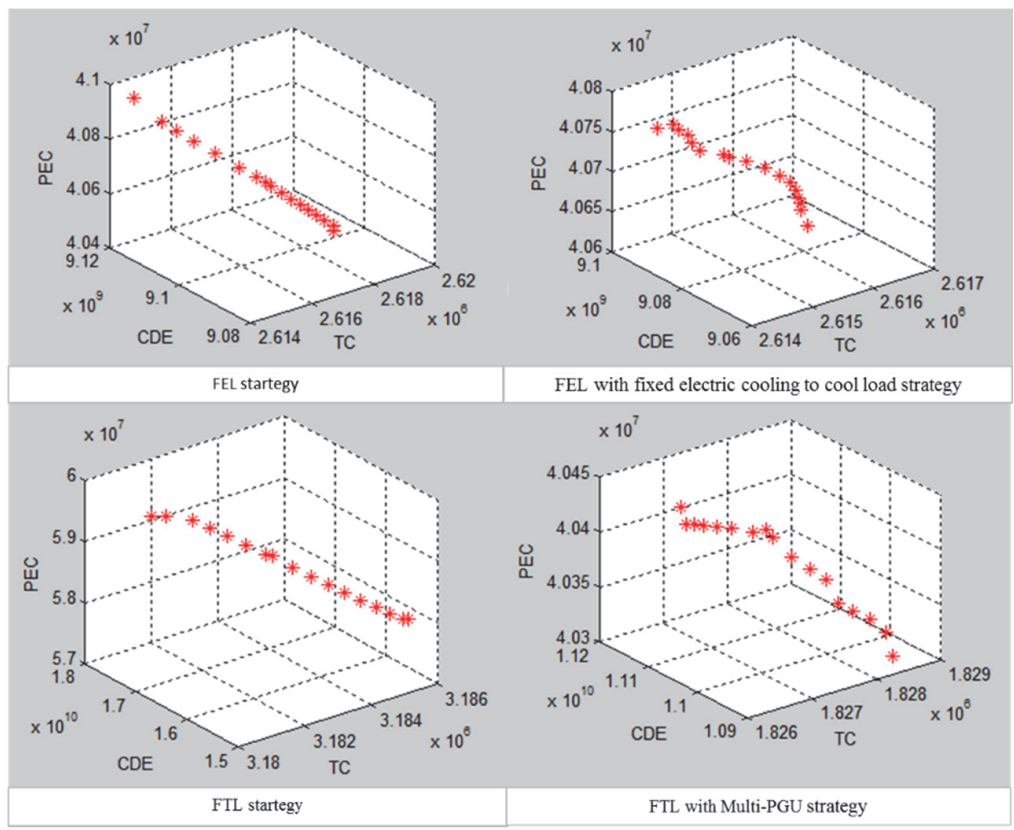

Fig. 6. Objectives amount for different strategies in different weights 


\subsection{Results for FEL strategy}

The best design of the system in this strategy is presented in the Table 7 for both the GA and PSO algorithm. PSO outperforms GA in this settings as reflected in the last three rows of Table 7. Numerical results in various segments of the system are shown in Fig. 7. Following this strategy, PGU is operating in its maximum capacity in 5870 periods and in partial load larger than 0.8 in 8684 periods (see Fig. 7 d. E PGU). The results regarding the heat storage tank (Fig. 7 c. Q Storage) indicate that during two periods of time the storage tank discharges completely. First in summer, to fulfil the heat requirement of the absorption chiller; and second in the winter, to meet the heat demand of the buildings. As shown in Fig. 7 a. Q Boiler, the thermal load provided by the boiler is maximized during winter, because recovered heat from the PGU is not sufficient to fulfil the heat demand of the system and the boiler supplies the remaining heat demand. In summer, the boiler is operational in 21 periods because recovered heat is not sufficient to fulfil absorption chiller's heat demand. As shown in Fig. 7 b. Q Electric Chiller, despite the priority given to the use of electric chiller under this strategy, only $34 \%$ of the cooling demand is supplied with electric chiller and the remaining cooling demand is fulfilled by the absorption chiller.

Table 7

Best design of the system at FEL strategy

\begin{tabular}{lll}
\hline Decision Variable & PSO Results & GA Results \\
\hline Nominal power of prime movers $(\mathrm{kW})$ & 1,345 & 1,489 \\
the on-off coefficient of PGU & 0.73 & 0.65 \\
Boiler heating capacity $(\mathrm{kW})$ & 3,883 & 3,617 \\
Electrical chiller cooling capacity $(\mathrm{kW})$ & 1,046 & 1,480 \\
Absorption chiller cooling capacity (kW) & 2,801 & 2,368 \\
Storage tank heating capacity $(\mathrm{kW})$ & 2,263 & 2,126 \\
Annual Total Cost $(\$)$ & $2,615,183$ & $2,631,256$ \\
Carbon Dioxide Emission $(\mathrm{gr})$ & $9,089,898,936$ & $9,125,387,007$ \\
Primary Energy Consumption $(\mathrm{kWh})$ & $40,707,123$ & $40,787,638$ \\
\hline
\end{tabular}

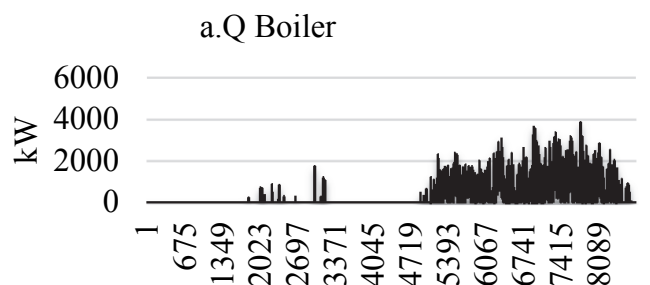

Hour

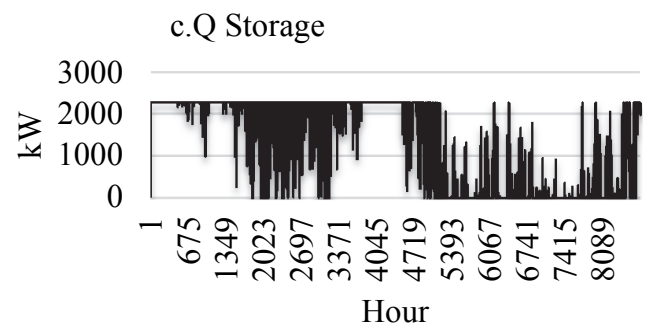

b.Q Electric Chiller

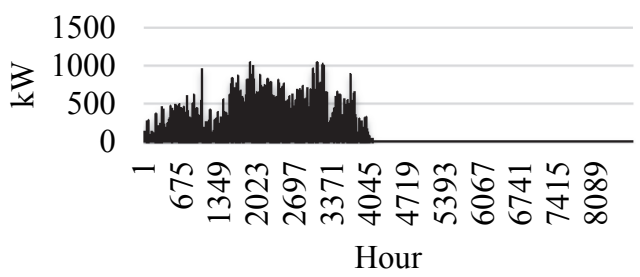

d.E PGU

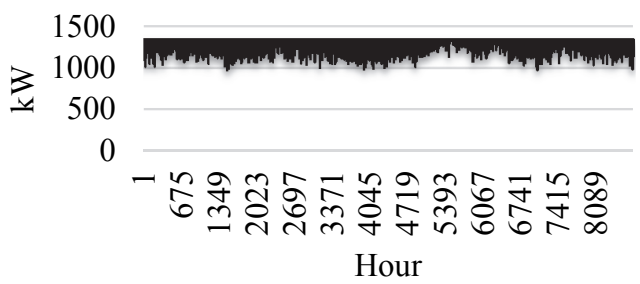

Fig. 7. Performance of system all year long under FEL 


\subsection{Results for FTL strategy}

The obtained results for this strategy are listed in Table 8. The on-off coefficient factor $(\alpha)$ is valued at the lowest limit (0.2). When the PGU is turned off the heat requirement of the buildings has to be provided by the boiler as shown in Fig. 8 d. Q Boiler. The priority in this strategy is with the absorption chiller, thus, cooling load provided by the absorption chiller throughout the year is more than FEL because, 98 $\%$ of cooling load is provided by the absorption chiller (c. Q Electric Chiller \& b. Q Absorption chiller). The electric chiller is used in 45 periods throughout the year. The obtained results from the FTL strategy are dominated by the results from the FEL strategy.

\section{Table 8}

Best design of the system at FTL strategy

\begin{tabular}{lll}
\hline Decision Variable & PSO Results & GA Results \\
\hline Nominal power of prime movers $(\mathrm{kW})$ & 2,140 & 2,665 \\
the on-off coefficient of PGU & 0.2 & 0.2 \\
Boiler heating capacity $(\mathrm{kW})$ & 3,840 & 3,207 \\
Electrical chiller cooling capacity $(\mathrm{kW})$ & 1258 & 817 \\
Absorption chiller cooling capacity $(\mathrm{kW})$ & 1,736 & 2,177 \\
Annual Total Cost $(\$)$ & $3,183,595$ & $3,198,811$ \\
Carbon Dioxide Emission $(\mathrm{gr})$ & $15,897,884,200$ & $16,012,517,593$ \\
Primary Energy Consumption $(\mathrm{kWh})$ & $58,687,631$ & $59,159,430$ \\
\hline
\end{tabular}

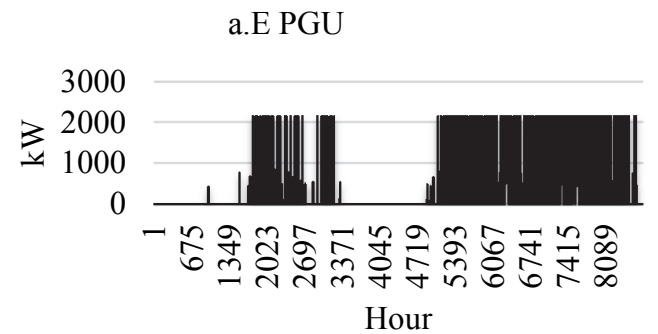

c.Q Electric Chiller

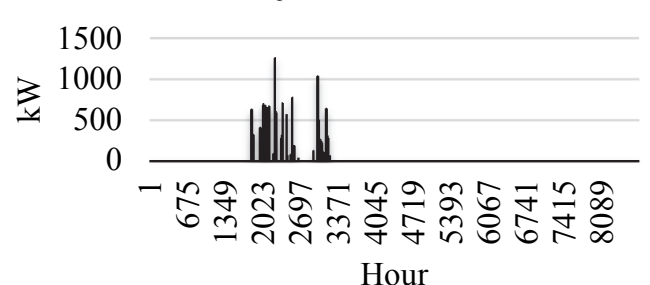

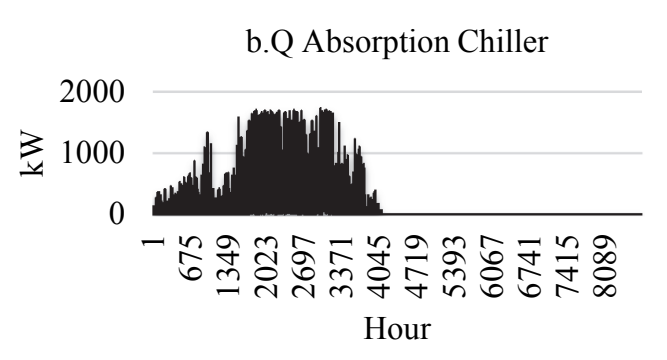

d.Q Boiler

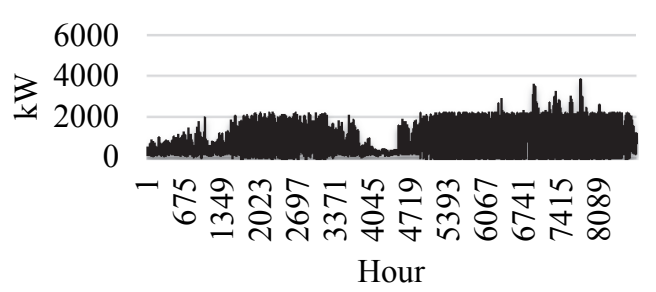

Fig. 8. Performance of system all year long (FTL)

In addition to higher economic costs, FTL strategy cause higher energy consumption and environmental pollution. In 6648 periods PGU is turned off as shown in Fig. 8 a. E PGU and power requirement of the system is supplied through the network which in addition to the cost of buying electricity imposes higher emissions and energy consumption to the system.

\subsection{Results for FEL, fixed electric cooling ratio}

The results of this strategy, shown in Table 9, indicate that best performance of the system is obtained when electric chiller supplies $24 \%$ of cooling demand of the system; the electric cooling to cool load ratio is set to 0.24 in the PSO as shown in Fig. 9 (d. Q Electric Chiller) and to 0.26 in the GA. The results 
show that this approach incurs less ATC, PEC and CDE than the two previous strategies. 96\% of the power requirement of the system is provided via PGU. The total heat requirement is $11,586,092 \mathrm{kWh}$ which is less than FTL $(11,924,618 \mathrm{kWh})$ and more than FEL $(11,436,859 \mathrm{kWh})$.

\section{Table 9}

Best design of the system at FEL, fixed electric cooling ratio strategy

\begin{tabular}{lll}
\hline Decision Variable & PSO Results & GA Results \\
\hline Nominal power of prime movers $(\mathrm{kW})$ & 1,488 & 1,507 \\
the on-off coefficient of PGU & 0.65 & 0.65 \\
Boiler heating capacity (kW) & 3,325 & 3,291 \\
Electrical chiller cooling capacity (kW) & 685 & 747 \\
Absorption chiller cooling capacity (kW) & 2,214 & 2,151 \\
Storage tank heating capacity (kW) & 1,743 & 1,735 \\
Electric cooling to cool load ratio & 0.24 & 0.26 \\
Annual Total Cost (\$) & $2,607,587$ & $2,611,042$ \\
Carbon Dioxide Emission (gr) & $9,015,246,427$ & $9,017,618,247$ \\
Primary Energy Consumption (kWh) & $40,111,759$ & $40,136,568$ \\
\hline
\end{tabular}

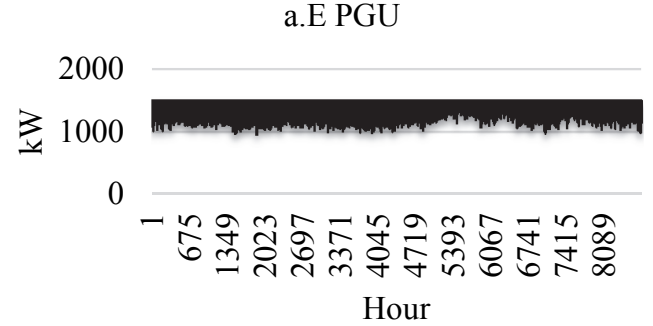

Hour

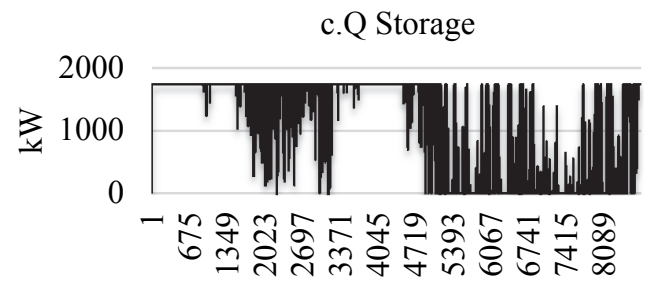

Hour
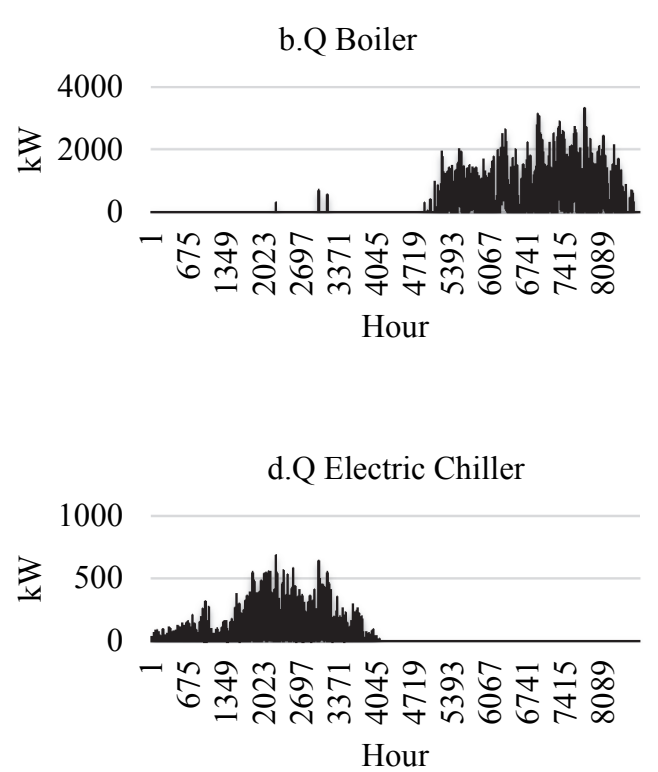

Fig. 9. Performance of system all year long (Fixed ratio of electric chiller cool load to cooling demand)

Heat required in this strategy is between FEL and FTL strategy because under the FEL strategy, the priority is with the electric chiller and heat requirement of the system will decrease. Under FTL and FEL strategies, the priority of the chillers is given so the performance of the chillers is partially predefined while under FEL with fixed electric cooling ratio, the model determines the best ratio of cooling load supplied by chillers; therefore, the results show a better performance. The capacity of the storage tank in this strategy is lower than under the FEL strategy (c. Q Storage). Following this strategy PGU operates in maximum capacity (a. E PGU) in 2974 periods and in 7761 periods operates in partial load above $80 \%$ of its capacity.

\subsection{Results for FEL multi PGU based on fixed electric cooling ratio}

The obtained results show that the selection of several PGUs in this strategy is not efficient and only increases the system costs. The reason is that PGU under the FEL strategy operates in partial load higher than $80 \%$ in 7761 periods indicating an efficient use of its capacity; as a result, selection of multiple PGUs does not improve the performance and only increases the capital cost of the system. So if the system is to operate based on FEL strategy, it is suggested to use a single PGU in this case study. 
As shown in Table 10 under FTL strategy using three PGUs is recommended. As shown Fig. 10 b. Q Boiler, a boiler with lower capacity compared to the previous strategies is chosen. This is because the recovered heat from the PGUs in most periods can fulfill the majority of the heat demand. Most of cooling demand is supplied by the absorption chiller which is more efficient and electric cooling to cool load ratio is 0.96 . In the peak of the heat demand, during winter and summer, all three units are in active status and operate in their maximum capacity as shown in Fig. 10 (a. E PGU). The costs of FTL strategy with one PGU is more than the FTL strategy with multiple PGUs. It is because at least one PGU is in the active mode with high partial load in 4805 periods, therefore, provided thermal and electrical load covers the demand.

Table 10

The best design of the system under the FTL strategy.

\begin{tabular}{lll}
\hline Decision Variable & PSO Results & GA Results \\
\hline Nominal power of prime movers1 $(\mathrm{kW})$ & 634 & 625 \\
Nominal power of prime movers2 $(\mathrm{kW})$ & 634 & 678 \\
Nominal power of prime movers2 $(\mathrm{kW})$ & 1152 & 1189 \\
the on-off coefficient of PGU & 0.71 & 0.70 \\
Boiler heating capacity $(\mathrm{kW})$ & 1,140 & 1,065 \\
Electrical chiller cooling capacity $(\mathrm{kW})$ & 172 & 156 \\
Absorption chiller cooling capacity $(\mathrm{kW})$ & 2,774 & 2,783 \\
Electric cooling ratio & 0.059 & 0.063 \\
Annual Total Cost $(\$)$ & $1,828,168$ & $1,829,785$ \\
Carbon Dioxide Emission $(\mathrm{gr})$ & $11,055,104,613$ & $11,061,070,542$ \\
Primary Energy Consumption $(\mathrm{kWh})$ & $41,219,129$ & $41,609,366$ \\
\hline
\end{tabular}
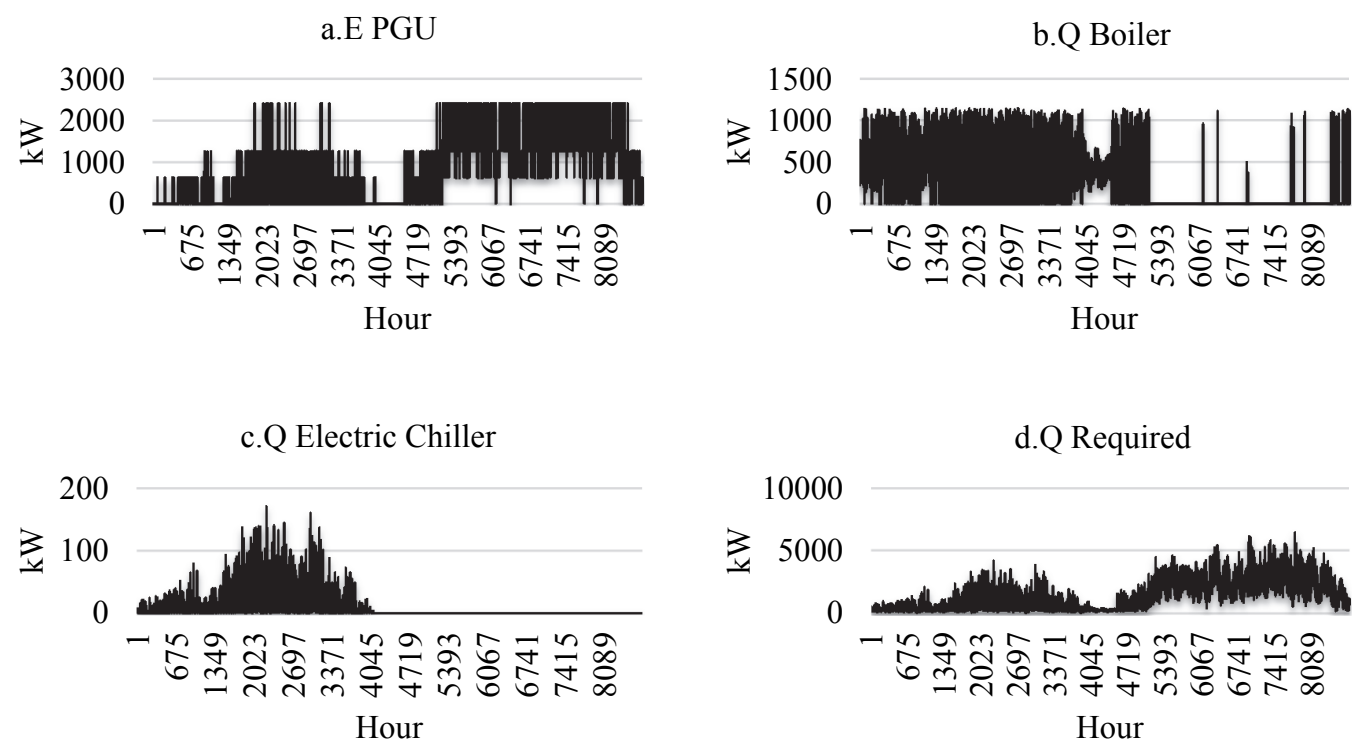

Fig. 10. Performance of system all year long (FTL, Multi PGU)

As a result, in addition to purchasing less electricity from the grid, less thermal load is supplied via auxiliary boiler in compression to the FTL strategy. 


\subsection{Electricity exchange with the grid}

Electricity exchanged with the grid under different strategies is shown in Fig. 11.

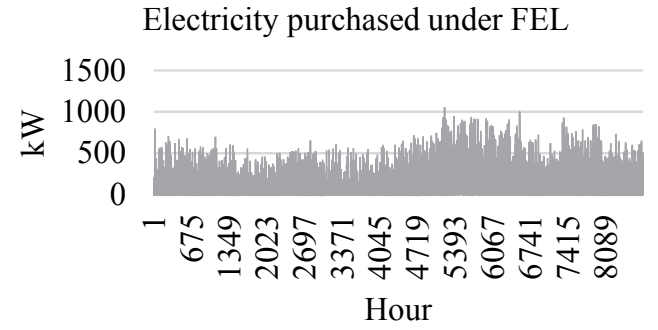

Electricity purchased under FEL by fixed ratio of chillers

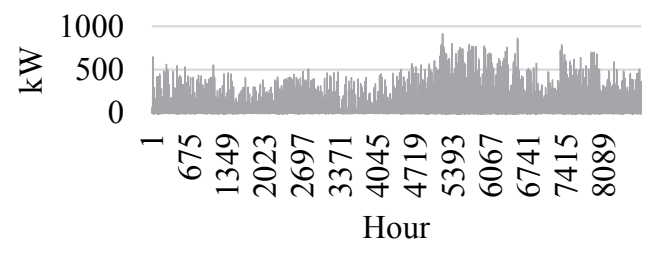

Electricity exchanged under

FTL

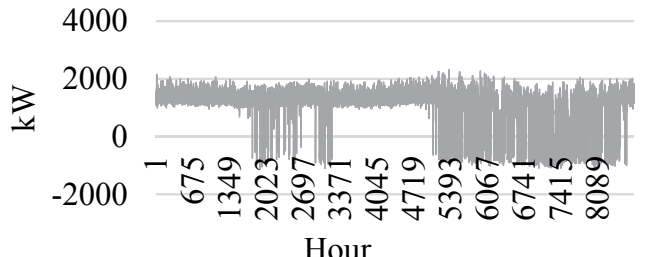

Electricity exchanged under FTLMultiple PGU

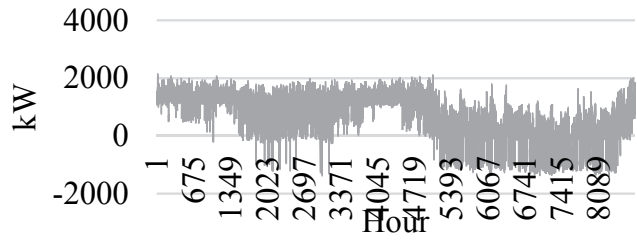

Fig. 11. Electricity exchanged with the grid

The total electricity purchased from the grid in FEL, FTL, FEL with fixed ratio of electric cooling to cool load, and FTL with multiple-PGU are respectively 1,070,688 kWh; 9,717,615 kWh; 516,235 kWh; and $7,081,472 \mathrm{kWh}$. Electricity sold to the grid in FTL and FTL with Multiple PGU are respectively 978,028 $\mathrm{kWh}$, and 1,026,760. Total electricity purchased form the grid under the FEL strategy with fixed ratio of electric cooling to cool load is less than the other strategies; so if increases in the price of electricity is predicted, this strategy's chance of being chosen by the decision makers increases. If the selling price of the electricity rises, multiple-PGU under FTL results less ATC which can alter the decision makers' decision.

\section{Conclusion}

A combined cooling, heating and power generation (CCHP) system was optimally designed. The decision variables were the number of prime movers (PGUs), their capacity and operational strategy, backup boiler, storage tank heating, absorption chiller and electric chiller capacity, electric cooling ratio, and the on-off coefficient of the PGU. This combination of the decision variables, along with the various strategies considered in this study, provide a more comprehensive view of the real system and, to the best of authors' knowledge, is presented for the first time. Due to the complexity of the developed model, PSO and GA were used to solve it. PSO showed a better performance in solving the optimisation problem although the difference between PSO and GA was maximum $0.7 \%$.

The results obtained for the case study show that under the FEL strategy, CDE and PEC are significantly reduced in compression to the FTL strategy. Under FTL strategy with one PGU, the PGU is put in the inactive mode in a large number of time. Under FTL strategy with multiple PGU significant reduction in costs was observed but, CDE and PEC were still higher in compression to the FEL strategy. If the approach of decision makers is to reduce the economic costs, it is better to work based on multi-PGU under FTL strategy; and if they rather to reduce CDE and PEC or are seeking to buy the lowest amount of electricity from the grid, system should work based on FEL strategy with fixed ratio of electric cooling to cool load. If selling price of electricity were rising, the system should operate based on multi-PGU 
under the FTL strategy; and if buying price of electricity were rising, system should operate based on the FEL strategy with fixed ratio of electric cooling to cool load.

As a direction for future research, analysing the potential usage of municipality waste in the presented case study, and generally biomass in other jurisdictions, as the primary source of energy in the CCHP systems is suggested. Another avenue of the future research could be the consideration of the chill storage tanks in the CCHP system and analysing its effect on system's performance. Also, estimating the input parameters such as electricity, cooling and heating demand of the CCHP by design of a system dynamic model or time series prediction is an interesting topic. These methods can be used to predict input data regarding energy consumption. When only the energy consumption data of last years and physical futures of the buildings are used to estimate energy demand of the system, the possible trends in the energy consumption of the system are neglected.

\section{Acknowledgement}

We thank Iranian Fuel Conservation Company (IFCO) for assistance with the case study, and $\mathrm{Mr}$ Mohammad Babagolzadeh for constructive discussions.

\section{References}

Arcuri, P., Florio, G., \& Fragiacomo, P. (2007). A mixed integer programming model for optimal design of trigeneration in a hospital complex. Energy, 32(8), 1430-1447.

Bahrami, S., \& Safe, F. (2013). A financial approach to evaluate an optimized combined cooling, heat and power system. Energy and Power Engineering, 5(05), 352.

Cai, W., Wu, Y., Zhong, Y., \& Ren, H. (2009). China building energy consumption: situation, challenges and corresponding measures. Energy Policy, 37(6), 2054-2059.

Cao, J. (2009). Evaluation of retrofitting gas-fired cooling and heating systems into BCHP using design optimization. Energy Policy, 37(6), 2368-2374.

Chen, B.-K., \& Hong, C.-C. (1996). Optimum operation for a back-pressure cogeneration system under time-of-use rates. Power Systems, IEEE Transactions on, 11(2), 1074-1082.

Črepinšek, M., Liu, S.-H., \& Mernik, M. (2013). Exploration and exploitation in evolutionary algorithms: A survey. ACM Computing Surveys (CSUR), 45(3), 35.

Eberhart, R. C., \& Kennedy, J. (1995). A new optimizer using particle swarm theory. Paper presented at the Proceedings of the sixth international symposium on micro machine and human science.

Energy Plus (2014). 8.5.0. . 2016, from www.energyplus.net

Ge, Y., Tassou, S., Chaer, I., \& Suguartha, N. (2009). Performance evaluation of a tri-generation system with simulation and experiment. Applied Energy, 86(11), 2317-2326.

Geidl, M., \& Andersson, G. (2007). Optimal power flow of multiple energy carriers. Power Systems, IEEE Transactions on, 22(1), 145-155.

Ghaebi, H., Saidi, M., \& Ahmadi, P. (2012). Exergoeconomic optimization of a trigeneration system for heating, cooling and power production purpose based on TRR method and using evolutionary algorithm. Applied thermal engineering, 36, 113-125.

Gibson, C. A., Meybodi, M. A., \& Behnia, M. (2015). How Carbon Pricing Impacts the Selection and Optimization of a Gas Turbine Combined Heat and Power System: An Australian Perspective. Journal of Clean Energy Technologies, 3(1).

International Energy Outlook. (2016). Retrieved 31 August, 2016, from http://www.eia.gov

Iran Energy Efficiency Organization (IEEO-SABA). (2016). Retrieved 31 August, 2016, from http://en.saba.org.ir

Iranian Electricity management. (2016). Retrieved 31 August, 2016, from www.tavanir.org.ir Iranian Fuel Conservation Organization. (2016). Retrieved 31 August, 2016, from www.ifco.org

Ito, K., Gamou, S., \& Yokoyama, R. (1998). Optimal unit sizing of fuel cell cogeneration systems in consideration of performance degradation. International Journal of Energy Research, 22(12), $1075-$ 1089. 
Karbassi, A., Abduli, M., \& Abdollahzadeh, E. M. (2007). Sustainability of energy production and use in Iran. Energy Policy, 35(10), 5171-5180.

Liu, M., Shi, Y., \& Fang, F. (2013). Optimal power flow and PGU capacity of CCHP systems using a matrix modeling approach. Applied Energy, 102, 794-802.

Løken, E. (2007). Use of multicriteria decision analysis methods for energy planning problems. Renewable and Sustainable Energy Reviews, 11(7), 1584-1595.

Mago, P., \& Chamra, L. (2009). Analysis and optimization of CCHP systems based on energy, economical, and environmental considerations. Energy and Buildings, 41(10), 1099-1106.

MATLAB. (2013). 2013. from http://www.mathworks.com/products/matlab/

Mitchell, M. (1998). An introduction to genetic algorithms: MIT press.

Pérez-Lombard, L., Ortiz, J., \& Pout, C. (2008). A review on buildings energy consumption information. Energy and Buildings, 40(3), 394-398.

Piacentino, A., \& Cardona, F. (2008). EABOT-energetic analysis as a basis for robust optimization of trigeneration systems by linear programming. Energy Conversion and Management, 49(11), 30063016.

Sanaye, S., \& Hajabdollahi, H. (2013). 4E analysis and Multi-objective optimization of CCHP using MOPSOA. Proceedings of the Institution of Mechanical Engineers, Part E: Journal of Process Mechanical Engineering, 0954408912471001.

Sanaye, S., \& Hajabdollahi, H. (2015). Thermo-economic optimization of solar CCHP using both genetic and particle swarm algorithms. Journal of Solar Energy Engineering, 137(1), 011001.

Sanaye, S., \& Khakpaay, N. (2014). Simultaneous use of MRM (maximum rectangle method) and optimization methods in determining nominal capacity of gas engines in CCHP (combined cooling, heating and power) systems. Energy, 72, 145-158.

Sanaye, S., Meybodi, M. A., \& Shokrollahi, S. (2008). Selecting the prime movers and nominal powers in combined heat and power systems. Applied thermal engineering, 28(10), 1177-1188.

Smith, A., Luck, R., \& Mago, P. J. (2010). Analysis of a combined cooling, heating, and power system model under different operating strategies with input and model data uncertainty. Energy and Buildings, 42(11), 2231-2240.

Tichi, S., Ardehali, M., \& Nazari, M. (2010). Examination of energy price policies in Iran for optimal configuration of CHP and CCHP systems based on particle swarm optimization algorithm. Energy Policy, 38(10), 6240-6250.

Wang, J.-J., Jing, Y.-Y., Zhang, C.-F., \& Zhao, J.-H. (2009). Review on multi-criteria decision analysis aid in sustainable energy decision-making. Renewable and Sustainable Energy Reviews, 13(9), 22632278.

Wang, J.-J., Xu, Z.-L., Jin, H.-G., Shi, G.-h., Fu, C., \& Yang, K. (2014). Design optimization and analysis of a biomass gasification based BCHP system: A case study in Harbin, China. Renewable Energy, 71, 572-583.

Wang, J., Jing, Y., Zhang, C., \& Zhang, B. (2008). Distributed combined cooling heating and power system and its development situation in China. Paper presented at the ASME 2008 2nd International Conference on Energy Sustainability collocated with the Heat Transfer, Fluids Engineering, and 3rd Energy Nanotechnology Conferences.

Wang, J., Zhai, Z. J., Jing, Y., \& Zhang, C. (2010). Particle swarm optimization for redundant building cooling heating and power system. Applied Energy, 87(12), 3668-3679.

Wang, J., Zhai, Z. J., Jing, Y., Zhang, X., \& Zhang, C. (2011). Sensitivity analysis of optimal model on building cooling heating and power system. Applied Energy, 88(12), 5143-5152.

Wang, Q., \& Fang, F. (2011). Optimal configuration of CCHP system based on energy, economical, and environmental considerations. Paper presented at the Intelligent Control and Information Processing (ICICIP), 2011 2nd International Conference on.

Wu, Z., Gu, W., Wang, R., Yuan, X., \& Liu, W. (2011). Economic optimal schedule of CHP microgrid system using chance constrained programming and particle swarm optimization. Paper presented at the 2011 IEEE Power and Energy Society General Meeting. 
Zheng, C., Wu, J., \& Zhai, X. (2014). A novel operation strategy for CCHP systems based on minimum distance. Applied Energy, 128, 325-335.

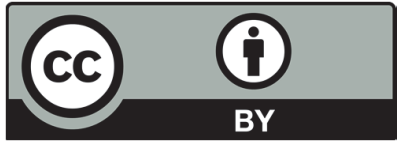

(C) 2017 by the authors; licensee Growing Science, Canada. This is an open access article distributed under the terms and conditions of the Creative Commons Attribution (CCBY) license (http://creativecommons.org/licenses/by/4.0/). 